\title{
PAPERS
}

\section{Effects of Helicobacter pylori infection on gastric acid secretion and serum gastrin levels in Mongolian gerbils}

\author{
M Takashima, T Furuta, H Hanai, H Sugimura, E Kaneko
}

\begin{abstract}
Background and aims-Body gastritis caused by Helicobacter pylori infection appears to inhibit gastric acid secretion. The aim of this study was to determine the effects of $H$ pylori infection on gastric acid secretion and clarify its mechanisms with reference to interleukin $1 \beta$ (IL-1ß).

Methods-(1) Mongolian gerbils were inoculated orally with $\boldsymbol{H}$ pylori. Before, six, and 12 weeks after inoculation, serum gastrin levels, gastric acid output, and IL-1及 mRNA levels in the gastric mucosa were determined. Pathological changes were also determined according to the updated Sydney system. (2) Effects of recombinant human IL-1 receptor antagonist (rhIL-1ra) on gastric acid output and serum gastrin levels were also determined.
\end{abstract}

Results-(1) Scores for activity and inflammation of gastritis and serum gastrin levels were significantly increased, and gastric acid output was significantly decreased six and 12 weeks after inoculation with $H$ pylori. IL-1及 mRNA levels in the gastric mucosa were also elevated six and 12 weeks after inoculation with $H$ pylori. (2) Acid output and serum gastrin levels in the infected groups returned to control levels after rhIL-1ra injection.

Conclusions-Gastric acid secretion is decreased and serum gastrin levels are increased in Mongolian gerbils infected with $H$ pylori. This change in gastric acid secretion appears to be mediated by IL-1 $\beta$ induced by $\boldsymbol{H}$ pylori infection.

(Gut 2001;48:765-773)

Keywords: Helicobacter pylori; interleukin 1 $\beta$; Mongolian gerbils; gastric acid; gastrin

Helicobacter pylori colonises the human gastric mucosa and causes chronic gastritis and peptic ulceration in some subjects. ${ }^{12}$ The effects of $H$ pylori infection on gastric acid secretion depend on several variables. It has been reported that basal and peak acid output, and plasma gastrin levels were significantly higher in patients with $H$ pylori positive duodenal ulcers than in $H$ pylori negative controls. ${ }^{34}$ In some patients with $H$ pylori related body gastritis, gastric acid output was low or absent, whereas acid secretion was improved and serum gastrin levels decreased significantly with eradication of $H$ pylori. ${ }^{5}$ In contrast, a large proportion of $H$ pylori infected non-ulcer patients have no abnormality in gastrin release or gastric acid output. ${ }^{6}$ Recently, we reported that the degree of acid suppression depended on the distribution of the H pylori infection and on the degree of gastritis in the body, and serum gastrin levels increased in patients with duodenal and gastric ulcers. ${ }^{7}$ However, the mechanisms by which $H$ pylori affects acid secretion are still unclear.

Interleukin $1 \beta$ (IL-1 $\beta$ ), which plays an important role in inflammatory and immunological responses, ${ }^{8}$ has been shown to inhibit gastric acid secretion in rats. ${ }^{9}{ }^{10}$ Production of IL-1 $\beta$ in gastric mucosa was increased in patients with $H$ pylori associated gastritis. ${ }^{11}{ }^{12}$ Recently, El-Omar et al reported that IL-1 gene polymorphisms, in relation to enhanced production of IL-1 $\beta$, were associated with an increased risk of hypochlorhydria induced by $H$ pylori infection in gastric cancer relatives. ${ }^{13}$

It has been reported that Mongolian gerbils can be easily infected with $H$ pylori, resulting in the occurrence of gastritis, ulcers, and neoplasms which mimic $H$ pylori positive patients with gastric ulcer and gastric cancer. ${ }^{14}{ }^{15}$ However, gastric acid secretion and IL-1 $\beta$ levels in the gastric mucosa of Mongolian gerbils have not been studied previously. Hence in this study we investigated the effects of $H$ pylori infection on gastric acid secretion and serum gastrin levels in Mongolian gerbils. In addition, we examined if IL- $1 \beta$ was associated with acid secretion in this animal model infected with $H$ pylori.

\section{Methods}

ANIMALS

Six week old specific pathogen free male Mongolian gerbils (MGS/Sea), mean body weight $50 \mathrm{~g}$, were purchased from Seiwa Experimental Animal Ltd (Fukuoka, Japan) and housed in

Abbreviations used in this paper: IL- $1 \beta$, interleukin $1 \beta$; rhIL-1 ra, recombinant human IL-1 receptor antagonist; CFU, colony forming units; PCR, polymerase chain reaction. 
polycarbonate cages in isolators. They were fed a commercial rodent diet and provided with water ad libitum. All animal experimentation was performed in accordance with institutional guidelines.

BACTERIAL STRAINS, MEDIA, AND GROWTH A $H$ pylori standard strain (ATCC43504) was obtained from American Type Culture Collection (Maryland, USA). This strain is cytotoxin associated protein positive and vacuolating cytotoxin positive. The bacteria were grown on Brucella broth (BBL; Becton Dickinson and Co., Cockeyville, Maryland, USA) containing $10 \%$ horse serum and incubated for 24 hours under microaerobic conditions at $37^{\circ} \mathrm{C}$.

BACTERIAL INOCULATION

The culture of $H$ pylori $\left(0.5 \mathrm{ml}, 1 \times 10^{8}\right.$ colony forming units (CFU)) was administered orally, using a feeding needle, to Mongolian gerbils after fasting for 24 hours. ${ }^{16}$ Brucella broth without $H$ pylori was given to the control groups. Four hours after inoculation, Mongolian gerbils were fed and housed in the same manner as the former for six and 12 weeks.

MEASUREMENT OF GASTRIC ACID OUTPUT AND SERUM GASTRIN LEVELS

Six and 12 weeks after inoculation, nine Mongolian gerbils infected with $H$ pylori and nine control gerbils were operated on and studied. The pylorus was ligated under ether anaesthesia to trap gastric juice in the stomach. After operation for pylorus ligation, the gerbils woke up from anaesthesia and were housed in cages without food or water for three hours. Three hours later, Mongolian gerbils were sacrificed under ether anaesthesia. The stomach was immediately removed and opened along the greater curvature. Whole stomach weight was measured. The longitudinal half of the stomach was used for quantitative determination of $H$ pylori and the other half of the stomach was used for histological examination and extraction of RNA for analysis of IL- $1 \beta$ mRNA. Blood samples were obtained to determine serum gastrin levels. Gastric juice was collected, the volume was measured, and concentrations of acid were determined by titration with $0.1 \mathrm{~N} \mathrm{NaOH}$ to $\mathrm{pH} 7.0$ on an automatic titrator (TOA Electronics Ltd., Tokyo, Japan). Serum gastrin levels were measured using a gastrin radioimmunoassay kit (Gastrin-RIA Kit II; Dainabot Co., Ltd, Tokyo, Japan) and the polyethylene glycol method. Antibodies used in this gastrin radioimmunoassay method strongly recognise the tyrosin residue at position 12 and the methionyl residue at position 15 on gastrin $(1-17)$. As a result, intraand interassay coefficients were $3.8-5.5 \%$ and $3.8-6.7 \%$, respectively. Mean recovery of gastrin added to serum samples was 106 $(12.2) \%$. Nine animals that were six week old were sacrificed before $H$ pylori inoculation and acid output and serum gastrin levels measured as described above.
INJECTION OF INTERLEUKIN 1 RECEPTOR ANTAGONIST

Recombinant human IL-1 receptor antagonist (rhIL-1 ra) was overexpressed in Escherichia coli as a $17 \mathrm{kd}$ protein by cloning IL-1 ra cDNA into a non-fused expressing vector provided by China Newtech Development and Trade Corporation (Beijing, China). Nine Mongolian gerbils infected with $H$ pylori and nine control gerbils 12 weeks after inoculation were injected with rhIL-1 ra intraperitoneally at a dose of 10 units/g, immediately after pylorus ligation. Three hours later they were sacrificed. Gastric acid output and serum gastrin levels were analysed as described above.

QUANTIFICATION OF VIABLE $H$ PYLORI

After the stomach was opened along the greater curvature, the longitudinal half of the stomach was homogenised in $10 \mathrm{ml}$ of phosphate buffered saline with a Polytron (Kinetica, Steinhofhalde, Sweden). Aliquots $(100 \mu \mathrm{l})$ of the dilutions were applied to the plated agar media containing vancomycin $(10 \mathrm{mg} / \mathrm{l})$, polymyxin B (2500 IU/1), and amphotericin B (2 $\mathrm{mg} / \mathrm{l}$ ) for isolation of $H$ pylori (Poamedia, Eikenkagaku Co., Ltd, Tokyo, Japan). The plates were incubated for seven days at $37^{\circ} \mathrm{C}$ under microaerobic conditions. Gram negative and oxidase, catalase, and urease positive spiral curved rods were identified as $H$ pylori. The number of colonies was determined. The number of viable $H$ pylori was expressed as CFU per stomach.

\section{HISTOPATHOLOGY}

Each stomach was fixed in $10 \%$ neutral buffered formalin. After fixation, a strip from the stomach, extending from the antrum to the body, was collected and embedded in paraffin. Strips were sectioned into $4 \mu \mathrm{m}$ pieces and stained with haematoxylin-eosin and Giemsa.

In the present study, one pathologist semiquantitatively scored the strips blindly without knowledge of $H$ pylori status or duration of infection. In each strip, microscopic investigations were performed to document histopathological changes. Polymorphonuclear neutrophil activity, chronic inflammation, glandular atrophy, intestinal metaplasia, and $H$ pylori density in the gastric mucosa were graded 0,1 , 2 , and 3 according to the updated Sydney system. ${ }^{17}$

SEQUENCE ANALYSIS OF MONGOLIAN GERBIL IL- $1 \beta$ GENE AND $\beta$-ACTIN GENE

To identify Mongolian gerbil IL- $1 \beta$ complimentary DNA (cDNA) clones, we selected similar parts of the sequence between murine IL-1 $\beta$ cDNA and the related sequence of human IL-1 $\beta$ in the biologically active portion. ${ }^{18-20}$ We chose a forward primer (corresponding to human IL-1 $\beta$ positions 44454462 in exon 4) and a reverse primer (positions 6673-6691 in exon 6) for polymerase chain reaction (PCR) (fig 1), and we amplified a segment of approximately $296 \mathrm{bp}$ from the cDNA in the gastric mucosa of Mongolian gerbils. The PCR product was cloned into pCRII using the original TA cloning kit (Invitrogen, San 
Forward primer for Mongolian gerbil IL-1 $\beta$ 5'-CTGAAAGCTCTCCACCTC-3'

Reverse primer for Mongolian gerbil IL-1 $\beta$ 5'-GTGCTGATGTACCAGTTGG-3'

Forward primer for $\beta$-actin 5'-GCACCACACCTTCTACAATGAG-3'

Reverse primer for $\beta$-actin 5'-ATAGCACAGCCTGGATAGCAAC-3'

Competitive template for Mongolian gerbil IL- $\beta$ 5'-CTGAAAGCTCTCCACCTCAATGGAGAGAATATAAACCAACAAGTGGTTTTC TCCATGAGCCCCACCCTGCAGCTGGAGAAGCGGTTTGTCTTCAACAAGATAG AAGTCAAAATTCGAGTCTGCACACTCCCCCAACTGGTACATCAGCAC-3'

Competitive template for $\beta$-actin 5'-ATAGCACAGCCTGGATAGCAACGTACATGGCTGGGGTGTTGAAGGTCTCA AACATGATAGCTCATTGTAGAAGGTGTGGTGC-3'

Figure 1 Oligonucleotide sequences of polymerase chain reaction (PCR) primers and competitive templates. The primer pair for Mongolian gerbil interleukin $1 \beta$ (IL-1 $\beta$ ) amplifies a $296 \mathrm{bp}$ band. The primer pair for $\beta$-actin amplifies a $164 \mathrm{bp}$ band. The competitive template for Mongolian gerbil IL-1 $\beta$ is $150 \mathrm{bp}$ long, and that for $\beta$-actin is 82 bp long. PCR products of $c D N A$ are distinguished by size from those of competitors.

Diego, California, USA). The nucleotide sequence of the insert was determined by the dideoxy chain termination procedure. ${ }^{21}$

To identify Mongolian gerbil $\beta$-actin cDNA clones, we chose one forward primer (corresponding to human $\beta$-actin positions 390-411) and one reverse primer (positions 973-993) (fig 1). ${ }^{22}$ We amplified a segment of approximately $164 \mathrm{bp}$ from the cDNA and determined the sequence as mentioned above.

ANALYSIS OF IL-1 $1 \beta$ BY QUANTITATIVE REVERSE TRANSCRIPTION-POLYMERASE CHAIN REACTION Total RNA was extracted from the gastric mucosa of the Mongolian gerbil soon after removing the stomach. RNA extraction was performed using an RNA extraction kit (RNA zoll; Tel-Test, Inc., Friendswood, Texas, USA). After DNase treatment, a $5 \mu \mathrm{g}$ portion of total RNA solution was subjected to reverse transcription using $200 \mathrm{U}$ of reverse transcriptase (Superscript Rnase H-Reverse Transcriptase; Gibco BRL, Life Technologies, Inc., Rockville, Maryland, USA).

The primer pair for Mongolian gerbil IL-1 $\beta$ (fig 1) amplifies the $296 \mathrm{bp}$ band from the cDNA. For competitive PCR, we prepared a competitive template (competitor) containing the same primer binding and a subset of the same template sequences as the target competing for primer binding and amplification (fig 1). The PCR products are distinguished by size (cDNA 296 bp; competitor 150 bp). Nine precise 10 -fold serial dilutions ranging from $1.0 \times 10^{3} \mathrm{pg} / \mu \mathrm{l}$ to $1.0 \times 10^{-1} \mathrm{pg} / \mu \mathrm{l}$ of competitor template were prepared.

We prepared a master mix containing, in a final volume of $50 \mu \mathrm{l}$, Mongolian gerbil IL-1 $\beta$ forward primer and reverse primer $(0.5 \mu \mathrm{M}$ each as the final concentration), dNTPs (200 $\mu \mathrm{l}$ each as the final concentration), $5 \mu \mathrm{l}$ of $10 \times$ PCR buffer, 1.25 units of Taq polymerase (Ex taq; Takara Shuzo, Shiga, Japan), and $2.0 \mu \mathrm{l}$ of cDNA solution. An aliquot of $48 \mu \mathrm{l}$ of this mixture was added to $2.0 \mu \mathrm{l}$ of previously prepared competitive template of known concentration in several dilution series. PCR was performed with an automatic thermal cycler (DNA Thermal Cycler PJ2000; Perkin-Elmer,
Norwalk, Conneticutt, USA). After heating at $94^{\circ} \mathrm{C}$ for five minutes, the samples were immediately cycled 35 times with a one minute denaturing step at $94^{\circ} \mathrm{C}$, one minute primer annealing step at $55^{\circ} \mathrm{C}$, and one minute extension step at $72^{\circ} \mathrm{C}$. The final cycle included extension for eight minutes at $72^{\circ} \mathrm{C}$ to ensure full extension of the product.

The completed reactions were analysed by electrophoresis of a $10 \mu \mathrm{l}$ aliquot through $3.0 \%$ (wt/vol) agarose gels containing $0.5 \mu \mathrm{g} / \mathrm{ml}$ ethidium bromide. The bands were visualised by excitation with UV light, and 296 bp (Mongolian gerbil IL-1 $\beta$ ) and $150 \mathrm{bp}$ (competitor) bands were detected (fig 2A). The gel was photographed, and the intensity of ethidium bromide luminescence was measured with a CCD image sensor (Densitograph AE-6900-F; Atto, Tokyo, Japan). The ratio of the $296 \mathrm{bp}$ (cDNA) to the $150 \mathrm{bp}$ (competitor) band was plotted for each dose of competitor added to the reaction tube. The point of equivalence (that is, where there was a $1: 1$ ratio) was where IL- $1 \beta$ equalled the competitor and represented the concentration of IL-1 $\beta$ mRNA in the unknown (fig 3).

The amount of $\beta$-actin mRNA was also measured by a similar method (fig $2 \mathrm{~B}$ ). The sequences of oligonucleotide primers for $\beta$-actin and the competitive template are shown in fig $1 .^{23}$ The amount of IL-1 $\beta$ mRNA in the gastric mucosa was standardised by $\beta$-actin and expressed as the ratio IL- $1 \beta / \beta$-actin.

\section{STATISTICAL ANALYSIS}

All numerical data are expressed as mean (SEM). For statistical analysis, a Statview software package (Hulinks, Tokyo, Japan) for Macintosh (Apple Computer, Inc., Cupertino, California, USA) was used. The statistical significance of the differences in gastric acid output, serum gastrin levels, body weights, stomach weights, and gastric juice volume between the infected and control groups were determined by Student $t$ test. Differences between values before, six, and 12 weeks after inoculation were determined by two way ANOVA with

$A$

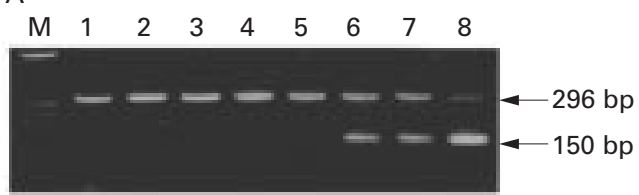

B

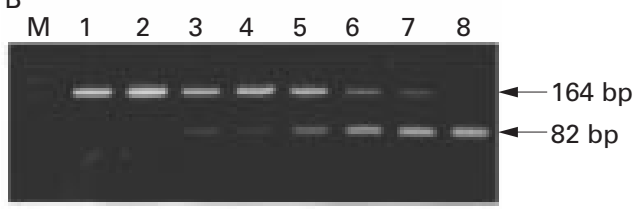

Figure 2 (A) Mongolian gerbil interleukin $1 \beta$ (IL-1 $\beta$ ) (296 bp) versus competitor (150 bp). Lane $M$ is the size marker ( $₫ 1174$ digested with Hae III). Lanes 1-8 contain eightfold serial amounts of competitor DNA ranging from $1.0 \times 10^{-0.5}$ pg/ul to $1.0 \times 10^{3}$ pg/ul competing against a fixed dose of cDNA. (B) $\beta$-actin (164 bp) versus competitor $(82$ $b p$ ). Lane $M$ is the size marker (øX174 digested with Hinf I). Lanes 1-8 contain eightfold serial amounts of competitor DNA ranging from $1.0 \times 10^{0.5} \mathrm{pg} / \mu \mathrm{l}$ to $1.0 \times 10^{3} \mathrm{pg} / \mu \mathrm{l}$ competing against a fixed dose of $c D N A$. 

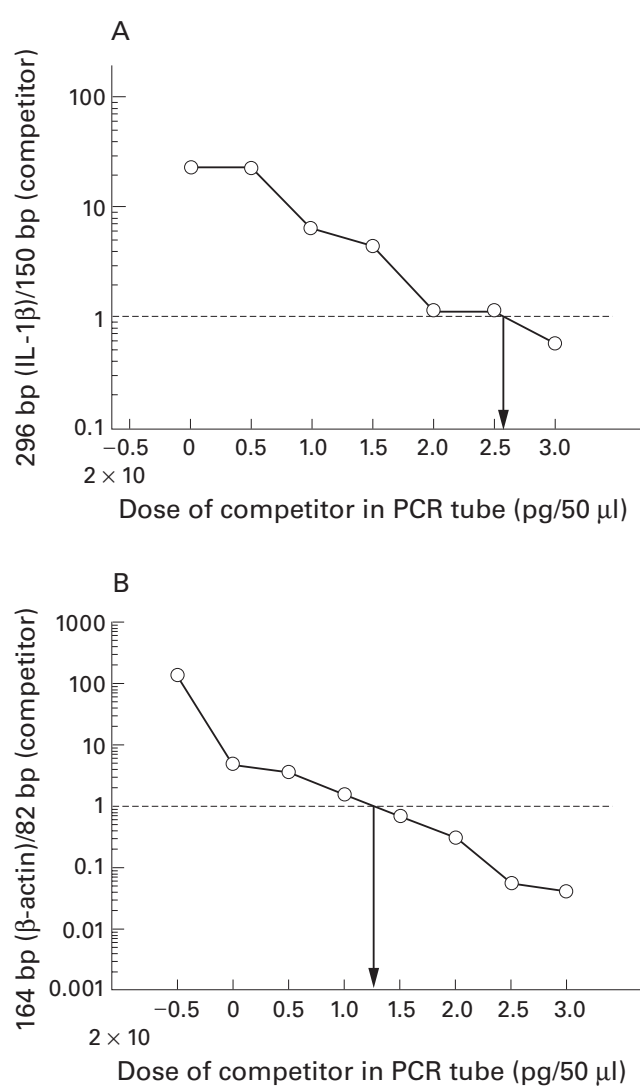

Figure 3 (A) Logarithmic plot of the ratio of Mongolian gerbil interleukin $1 \beta$ (IL-1 $\beta, 296 \mathrm{bp}$ ) to competitor $(150$ $b p)$, corresponding to fig $2 A$. The quantity of $I L-1 \beta m R N A$ in the reaction tube was determined by calculating how much of the competitor was required to achieve equal amounts of product. The amount of IL-1 $\beta m R N A$ was then calculated by extrapolating from the intersection of the curves to the $x$ axis where the amounts of IL-1B (296 bp) and competitor were equal. (B) Logarithmic plot of the ratio of $\beta$-actin (164 bp) to competitor ( $82 \mathrm{bp})$, corresponding to fig $2 \mathrm{~B}$.

Fisher's multiple comparison test. Effects of rhIL-1 ra on gastric acid output and serum gastrin levels in the infected and control groups were determined by one way ANOVA with Fisher's multiple comparison test. The statistical significance of the differences in gastritis scores between the infected and control groups were determined by the Mann-Whitney U test. Differences resulting in $\mathrm{p}$ values $\leqslant 0.05$ were considered significant.

\section{Results}

H PYLORI INFECTION, BODY WEIGHTS, AND STOMACH WEIGHTS OF MONGOLIAN GERBILS $H$ pylori was detected in all infected animals throughout the study. The number of viable $H$ pylori in the stomach reached $10^{5.0} \mathrm{CFU} /$ gastric wall at six weeks and remained at $10^{5.1} \mathrm{CFU}$ at 12 weeks (table 1). Body weights of Mongolian gerbils time dependently increased from before to six and 12 weeks after inoculation but there were no significant differences between the infected and control groups (table 1).

Stomach weights of Mongolian gerbils at six and 12 weeks after inoculation significantly increased compared with those before inoculation, and stomach weights of the infected groups were significantly heavier than those of the control groups, but no significant changes were observed from six to 12 weeks after inoculation (table 1).

\section{HISTOPATHOLOGY}

Marked infiltration of neutrophils and lymphocytes, mainly in the submucosa, spreading from the antrum to the body and focal aggregates of lymphocytes in the submucosa at the glandular border of the antrum and body, were observed in Mongolian gerbils infected with $H$ pylori, at both six and 12 weeks after inoculation. In contrast, infiltrations of neutrophils and lymphocytes were few or none in the control groups (fig 4). Scores for activity were significantly higher in the infected groups than in the control groups at both six $(\mathrm{p}<0.001)$ and $12 \quad(\mathrm{p}<0.001)$ weeks after inoculation. Scores for activity six and 12 weeks after $H$ pylori inoculation were significantly increased compared with those before inoculation $(\mathrm{p}=0.0001, \mathrm{p}<0.01)$ (fig $5 \mathrm{~A})$. Scores for inflammation were significantly higher in the infected groups than those of the control groups both six $(p=0.0001)$ and 12 $(\mathrm{p}<0.0001)$ weeks after inoculation. Scores for inflammation six and 12 weeks after $H$ pylori inoculation were significantly increased compared with those before inoculation $(p=0.0001, p=0.0001$ ) (fig $5 B$ ). No significant changes in glandular atrophy were observed between the infected and control groups at both six and 12 weeks after inoculation. There was a tendency for detectable colonies of $H$ pylori to be accompanied by both neutrophil and lymphocytic infiltration (data not shown). Slight goblet cell metaplasia was detected only in a few cases in the infected groups 12 weeks after inoculation (data not shown).

\section{GASTRIC JUICE VOLUME AND GASTRIC ACID} OUTPUT

The volume of gastric juice six and 12 weeks after inoculation was significantly increased compared with that before inoculation. Gastric juice volume was significantly greater in the

Table 1 Changes in body weight, stomach weight, and gastric juice volume as a function of Helicobacter pylori (HP) infection

\begin{tabular}{|c|c|c|c|c|c|}
\hline & \multirow[b]{2}{*}{ Before } & \multicolumn{2}{|l|}{6 weeks } & \multicolumn{2}{|l|}{12 weeks } \\
\hline & & $H P-$ & $H P+$ & $H P-$ & $H P+$ \\
\hline Body weight (g) & $42.8(0.9)$ & $73.3(2.8)$ & $69.4(1.8)$ & $76.3(2.1)$ & $78.3(2.0)$ \\
\hline Stomach weight (mg) & $468 \quad(10)$ & $508 \quad(15)$ & $791 \quad(20)^{\star \star \star}$ & $503 \quad(12)$ & $794(32)^{\star \star \star}$ \\
\hline Gastric juice volume $(\mu \mathrm{l})$ & $760 \quad(31)$ & $990 \quad(144)$ & $1690(178)^{\star \star}$ & $810 \quad(132)$ & $1650(256)^{\star \star}$ \\
\hline Colony count (log CFU) & & & $5.0(0.3)$ & & $5.1(0.2)$ \\
\hline
\end{tabular}

${ }^{\star} \mathrm{p}<0.05,{ }^{\star \star} \mathrm{p}<0.01,{ }^{\star \star \star} \mathrm{p}<0.0001$ versus control groups. 
infected groups than in the control groups (table 1).

Gastric acid output six and 12 weeks after $H$ pylori inoculation in the infected groups was significantly decreased compared with that before inoculation (29.6 (9.1), $22.5(4.3) v$ $51.5(6.2) \mu \mathrm{Eq} / 3$ hours; $\mathrm{p}<0.05, \mathrm{p}<0.01)$. Gastric acid output was significantly lower in the infected groups than in the control groups six weeks (29.6 (9.1) $v 61.1$ (9.8) $\mu \mathrm{Eq} / 3$ hours; $\mathrm{p}<0.05)$ and 12 weeks (22.5 (4.3) v 44.1 (5.9) $\mu \mathrm{Eq} / 3$ hours; $\mathrm{p}<0.01)$ after inoculation. No significant changes in gastric acid output were observed from before to six or 12 weeks in the control groups (fig 6).

SERUM GASTRIN LEVELS

Serum gastrin levels six and 12 weeks after $H$ pylori inoculation in the infected groups were significantly increased compared with those before inoculation (153.9 (13.4), 157.3 (10.2) $v 100.4$ (6.7) pg/ml; $\mathrm{p}<0.01, \mathrm{p}<0.001)$. Serum gastrin levels were significantly higher in the infected groups than in the control groups six weeks (153.9 (13.4) v 112.9 (9.2) pg/ml; $\mathrm{p}<0.05)$ and 12 weeks (157.3 (10.2) v 118.4 (3.4) $\mathrm{pg} / \mathrm{ml} ; \mathrm{p}<0.01$ ) after inoculation.

No significant changes in serum gastrin levels were observed in the control groups from before to six and 12 weeks after inoculation (fig 7).

SEQUENCE ANALYSIS OF MONGOLIAN GERBIL IL- $1 \beta$ GENE AND $\beta$-ACTIN GENE

Sequences of the 296 bp portion of IL-1 $\beta$ cDNA were aligned (fig 8A). The nucleotide sequences of Mongolian gerbil and human IL-1 $\beta$ were closely related (252 of 296 $(85.1 \%))$, and those of the Mongolian gerbil and murine IL-1 $\beta$ were also closely related
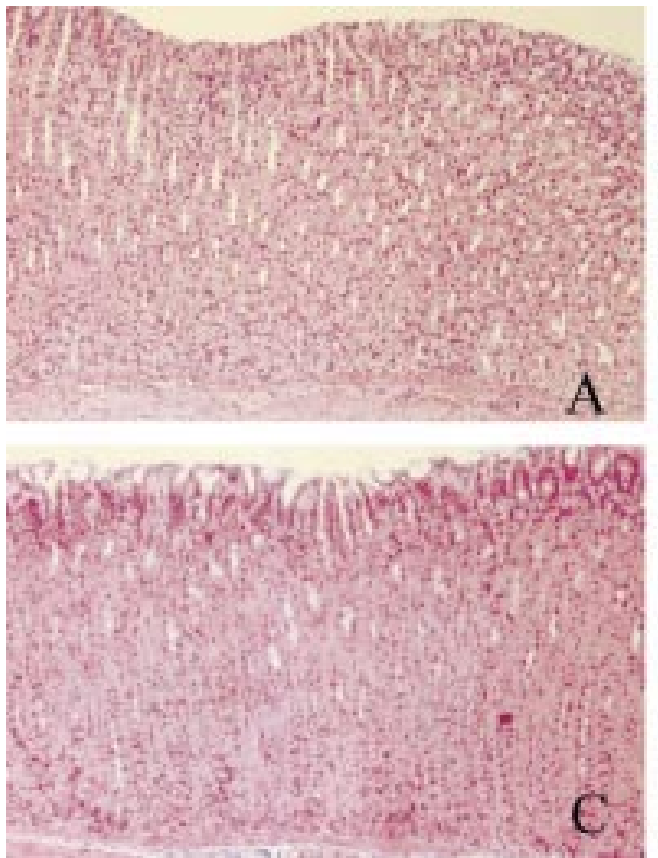

Figure 4 Histopathological changes in the gastric mucosa of Mongolian gerbils. (A) Inflammatory cell infiltrations were not observed in the control groups six weeks after inoculation. (B) Marked inflammatory cell infiltrations were observed in the infected groups six weeks after inoculation with $H$ pylori. (C) Inflammatory cell infiltrations were not observed in the control groups 12 weeks after inoculation. (D) Severe inflammatory cell infiltrations were observed in the infected groups 12 weeks after inoculation with $H$ pylori (haematoxylin-eosin, $\times 100)$.
(267 of $296(90.2 \%))$. We also aligned Mongolian gerbil, human, and murine $\beta$-actin (fig 8B). The nucleotide sequences of Mongolian gerbil and human $\beta$-actin were closely related (159/164: 97.0\%), and those of murine $\beta$-actin were also closely related to Mongolian gerbils (158/164: 96.3\%).

\section{IL-1 $\beta$ MRNA LEVELS}

IL- $1 \beta$ mRNA levels six and 12 weeks after $H$ pylori inoculation in the infected groups were significantly increased compared with those before inoculation (22.4 (8.6), 26.5 (6.2) $v 0.0$ $(0.0) ; \mathrm{p}<0.05, \mathrm{p}<0.01)$. IL-1 $\beta$ mRNA levels in the gastric mucosa were significantly higher in the infected groups than in the control groups both six and 12 weeks after inoculation (22.4 $(8.6) v 0.06(0.06)(\mathrm{p}<0.05)$ and $26.5(6.2) v$ $0.02(0.02)(\mathrm{p}<0.001))($ fig 9$)$.

EFFECTS OF RECOMBINANT HUMAN INTERLEUKIN 1 RECEPTOR ANTAGONIST (rhIL-1ra) ON GASTRIC ACID OUTPUT AND SERUM GASTRIN LEVELS

Gastric acid output in Mongolian gerbils infected with $H$ pylori after rhIL-1 ra injection significantly increased to control levels compared with the infected groups who did not receive rhIL-1 ra injection (45.1 (7.3) $v 22.5$ (4.3) $\mu \mathrm{Eq} / 3$ hours; $\mathrm{p}<0.05$ ), and was not significantly different from the control groups. No significant effects of rhIL-1 ra on gastric acid output were observed in Mongolian gerbils not infected with $H$ pylori (54.1 (10.7) $v$ 44.1 (5.9) $\mu \mathrm{Eq} / 3$ hours) (fig 10).

Serum gastrin levels in the Mongolian gerbils infected with $H$ pylori after rhIL-1ra injection significantly decreased to control levels compared with the infected groups without rhIL-1 ra injection (97.9 (5.8) $v 157.3$ (10.2)
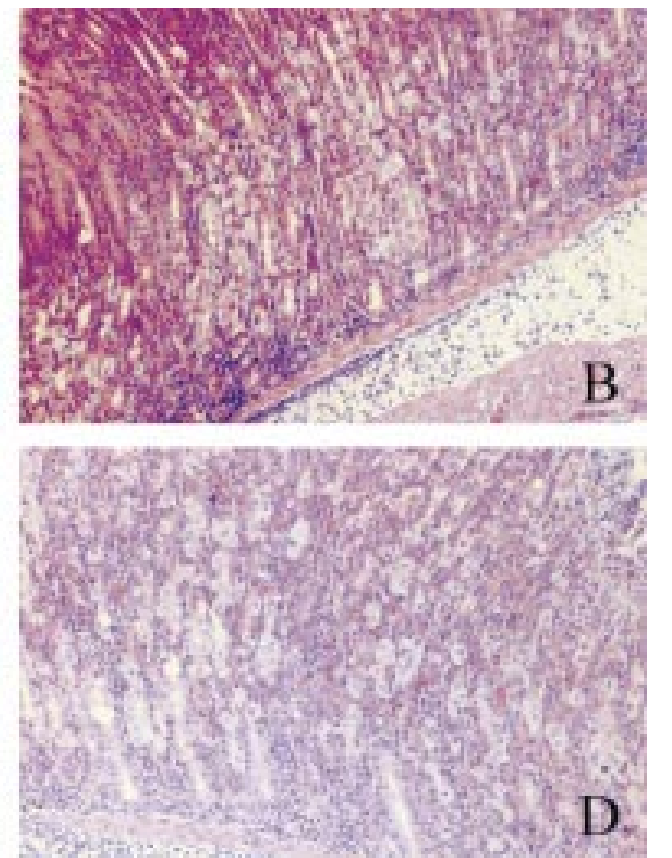

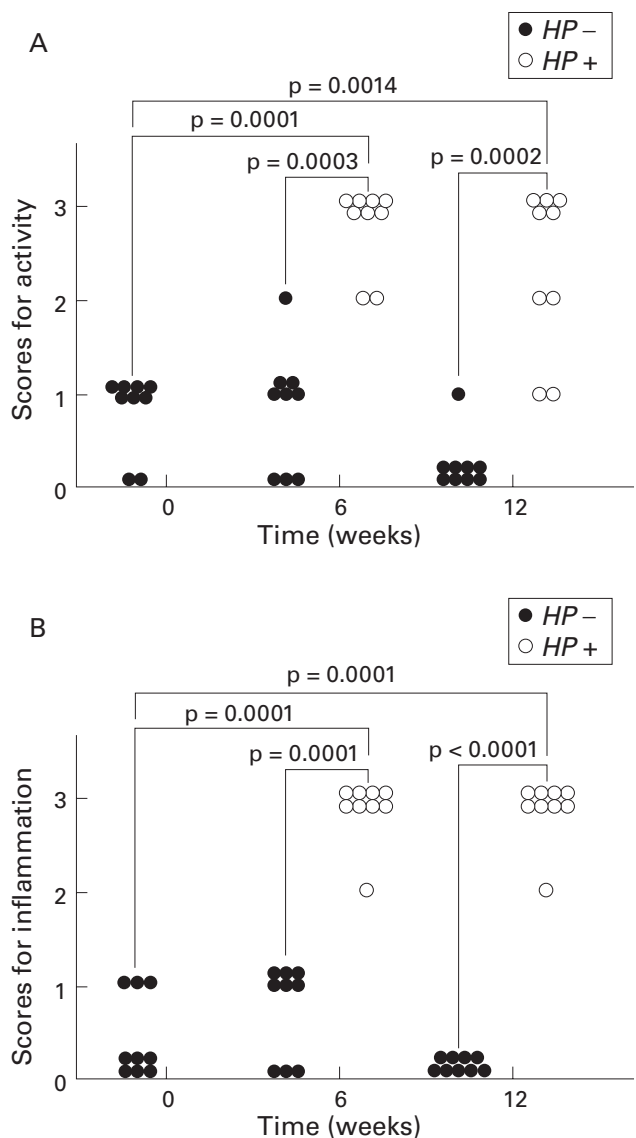

Figure 5 (A) Changes in gastritis scores for activity from before to six and 12 weeks after inoculation in the infected $($ Helicobacter pylori $(\mathrm{HP}+))$ and control $(\mathrm{HP}-)$ groups. The variables used for grading gastritis were rated on a four point scale: 0 , absent; 1 , mild; 2 , moderate; and 3 , severe, in accordance with the Sydney system. Gastritis scores for activity in the infected groups significantly increased six and 12 weeks after $H$ pylori inoculation. No significant changes were observed in the control groups. (B) Changes in gastritis scores for inflammation from before to six and 12 weeks after inoculation in the infected and control groups. Gastritis scores for inflammation in the infected groups significantly increased six and 12 weeks after $H$ pylori inoculation. No significant changes were observed in the control groups.

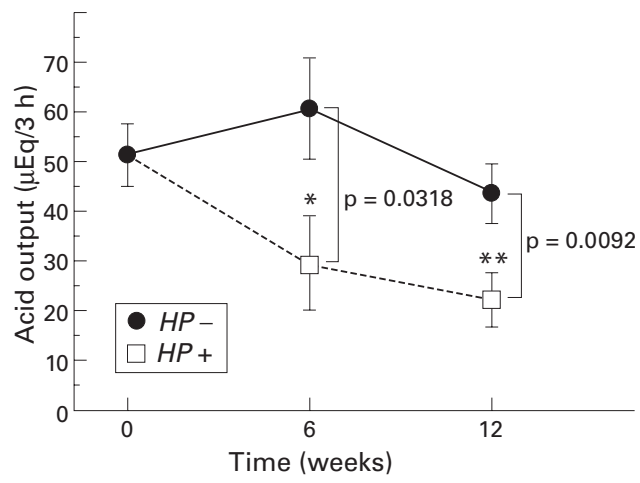

Figure 6 Changes in gastric acid output from before to six and 12 weeks after inoculation in the infected (Helicobacter pylori (HP+)) and control (HP-) groups. Gastric acid output in the infected groups significantly decreased six and 12 weeks after $H$ pylori inoculation. No significant changes were observed in the control groups. ${ }^{*} p=0.0328$; ${ }^{\star} p=0.0061$ compared with before inoculation.

$\mathrm{pg} / \mathrm{ml} ; \mathrm{p}<0.0001$ ), and were not significantly different from the control groups. No significant effects of rhIL-1 ra on serum gastrin levels were observed in Mongolian gerbils without $H$

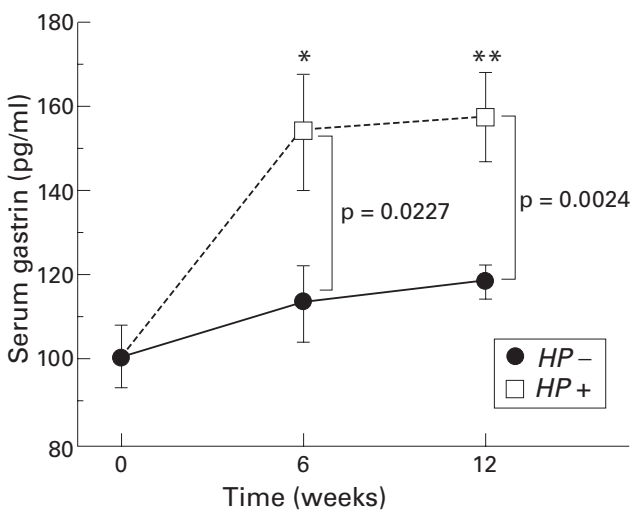

Figure 7 Changes in serum gastrin levels from before to 6 and 12 weeks after inoculation. Serum gastrin levels in the infected (Helicobacter pylori (HP+)) groups significantly increased six and 12 weeks after H pylori inoculation. No significant changes were observed in the control groups $(H P-) .{ }^{\star} p=0.0014 ;{ }^{\star}{ }^{\star} p=0.0008$ compared with before innoculation.

pylori infection (111.2 (7.5) $v 118.4$ (3.4) $\mathrm{pg} / \mathrm{ml}$ ) (fig 11).

\section{Discussion}

In the present study, we determined changes in gastric acid output after $H$ pylori infection and showed that $H$ pylori infection caused chronic active gastritis and suppressed gastric acid secretion, which was assumed to be mediated by IL-1 $\beta$.

Recent studies revealed that gastric acid hyposecretion observed in patients with body gastritis recovered soon after eradication of $H$ pylori as inflammation was improved, even though gastric atrophy and intestinal metaplasia had not improved significantly. ${ }^{524} 25$ Inflammation of the gastric mucosa caused by $H$ pylori infection may be closely related to gastric acid hyposecretion rather than atrophy. In the present study, severity of gastritis increased after $H$ pylori infection but no significant changes in glandular atrophy in the gastric mucosa of Mongolian gerbils with or without $H$ pylori infection were observed within the 12 week period of the present study. Therefore, gastric acid hyposecretion may not depend on glandular atrophy but on the severity of gastritis, at least for the duration of our study period.

$H$ pylori itself and several substances such as $N^{u}$-methyl histamine produced by $H$ pylor $i$ and cytokines induced by $H$ pylori infection, such as IL- $1 \beta$ and tumour necrosis factor $\alpha$, have been reported to inhibit gastric acid secretion. ${ }^{26-29}$ In particular, IL-1 $\beta$ is known as a potent inhibitor of acid secretion; peripheral and central administration of IL-1 $\beta$ potently inhibits gastric acid secretion in experimental animals. ${ }^{9}{ }^{10}{ }^{29-31}$ IL-1 $\beta$ also directly inhibits acid secretion by cultured rabbit parietal cells, ${ }^{32}$ and impairs the function of enterochromaffin-like cells in vitro, which may be followed by markedly decreased acid output. ${ }^{33}$ Moreover, IL-1 $\beta$ mRNA levels and IL-1 $\beta$ release significantly increased in the gastric mucosa of $H$ pylori positive patients. ${ }^{345}$ In the present study, IL-1 $\beta$ mRNA levels in the gastric mucosa of Mongolian gerbils infected with $H$ pylori were elevated in comparison with those of the 
A

424

5'-CTGAAAGCTCTCCACCTCAATGGAGAGAATATAAACCAACAAGTGGTTTTC 5'-CTGAAAGCTCTCCACCTCCAGGGACAGGATATGGAGCAACAAGTGGTGTTC 5'-CTGAAAGCTCTCCACCTCAATGGACAGAATATCAACCAACAAGTGATATTC 500

TCCATGAGCTTTGTACACGGTGACACAAGCAGCAACAAAATACCGGTGGCC TCCATGTCCTTTGTACAAGGAGAAGAAAGTAATGACAAAATACCTGTGGCC TCCATGAGCTTTGTACAAGGAGAACCAAGCAACGACAAAATACCTGTGGCC 550

TTGGGCCTCAAGGGAAAGAATCTGTACCTGTCCTGTGTGATGAAAGACGGC TTGGGCCTCAAGGAAAAGAATCTGTACCTGTCCTGCGTGTTGAAAGATGAT TTGGGCCTCAAAGGAAAGAATCTATACCTGTCCTGTGTAATGAAAGACGGC AGGCCCACCCTGCAGCTGGAGAGCGTGGACCCCAAACAATACCCGAAAAAG AAGCCCACTCTACAGCTGGAGAGTGTAGATCCCAAAAATTACCCAAAGAAG ACACCCACCCTGCAGCTGGAGAGTGTGGATCCCAAGCAATACCCAAAGAAG 650

AAGATGGAAAAGCGGTTTGTCTTCAACAAGATAGAAGTCAAATCCAAGGTG AAGATGGAAAAGCGATTTGTCTTCAACAAGATAGAAATCAATAACAAGCTG AAGATGGAAAAACGGTTTGTCTTCAACAAGATAGAAGTCAAGAGAAAAGTG 719 GCAC-3, Mongolian gerbil GAATTCGAGTCTGCACAGTTCCCCAACTGGTACATCAGCAC-3, Mongol GAATTTGAGTCTGCCCAGTTCCCCAACTGGTACATCAGCAC-3,' Human
GAGTTTGAGTCTGCAGAGTTCCCCAACTGGTACATCAGCAC-3, Mouse

B

260

300

5'-GCACCACACCTTCTACAATGAGCTGCGTGTGGCCCCCGAGGAGCACCCC 5'-GCACCACACCTTCTACAATGAGCTGCGTGTGGCTCCCGAGGAGCACCCC 5'-GCACCACACCTTCTACAATGAGCTGCGTGTGGCCCCTGAGGAGCACCC 350

GTGCTGCTCACCGAGGCTCCCCTGAACCCCAAGGCCAACCGTGAAAAGATG GTGCTGCTGACCGAGGCCCCCCTGAACCCCAAGGCCAACCGCGAGAAGATG GTGCTGCTCACCGAGGCTCCCCTGAACCCTAAGGCCAACCGTGAAAAGATG 400

ACCCAGATCATGTTTGAGACCTTCAACACCCCAGCCATGTACGTTGCTATC ACCCAGATCATGTTTGAGACCTTCAACACCCCAGCCATGTACGTTGCTATC ACCCAGATCATGTTTGAGACCTTCAACACCCCAGCCATGTACGTAGCCATC 423

CAGGCTGTGCTAT-3' Mongolian gerbil

CAGGCTGTGCTAT-3, Human

CAGGCTGTGCTGT-3' Mouse

Figure 8 (A) Alignment of the 296 bp portion of interleukin $1 \beta$ (IL-1 $\beta$ ) cDNA sequences for the Mongolian gerbil, human, and mouse. Oligonucleotides in bold type in human and mouse are different from those of Mongolian gerbil; $85.1 \%$ oligonucleotide identities were observed between Mongolian gerbil and human and 90.2\% between Mongolian gerbil and mouse. (B) Alignment of the $164 \mathrm{bp}$ portion of $\beta$-actin cDNA sequences for the three species. Oligonucleotides in bold type in human and mouse were different from those of the Mongolian gerbil; $97.0 \%$ oligonucleotide identities were observed between Mongolian gerbil and human and $96.3 \%$ between Mongolian gerbil and mouse.

control groups. In addition, gastric acid secretion in the infected groups was decreased in comparison with those of the control groups and recovered to control levels by rhIL-1ra. Therefore, IL- $1 \beta$ induced by $H$ pylori infection is assumed to play an important role in gastric acid hyposecretion observed in body gastritis patients.

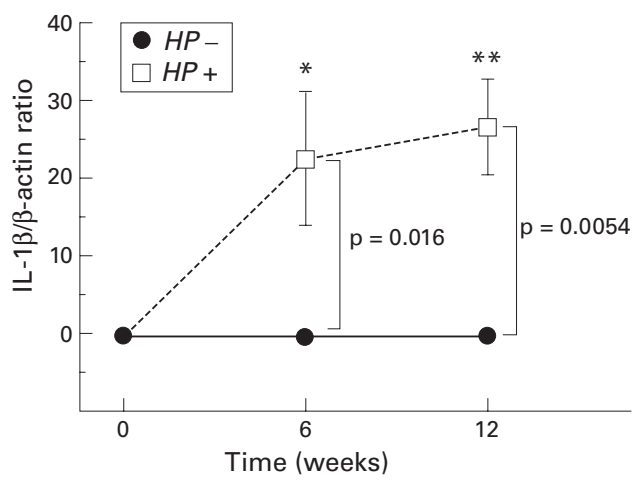

Figure 9 Changes in interleukin $1 \beta(I L-1 \beta) m R N A$ levels from before to six and 12 weeks after inoculation in the infected (Helicobacter pylori $(H P+))$ and control $(H P-)$ groups. Il-1 $\mathrm{mRNA}$ levels significantly increased six and 12 weeks after $H$ pylori inoculation. IL-1 $\beta$ mRNA was virtually undetected in the control groups throughout the study. ${ }^{\star} p=0.0191 ;{ }^{\star} p=0.0006$ compared with before innoculation.

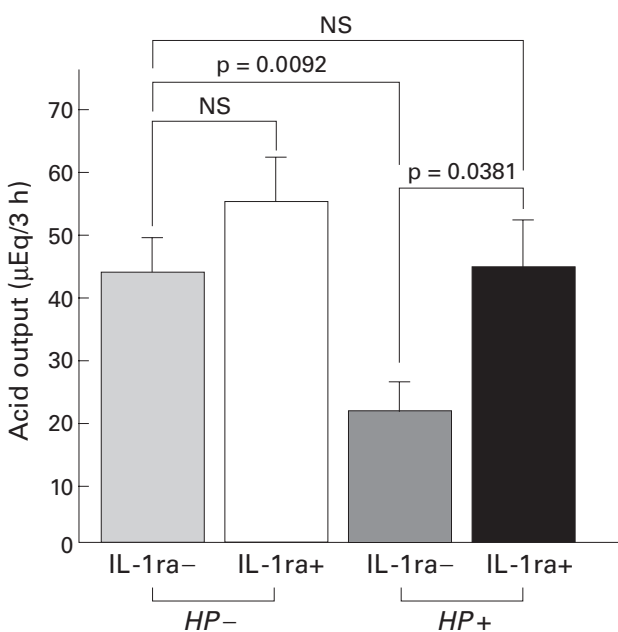

Figure 10 Gastric acid output with (+) or without (-) recombinant human $I L-1$ receptor antagonist (rhIL-1 ra) injection in the infected (Helicobacter pylori $(\mathrm{HP}+)$ ) and control (HP-) groups. Gastric acid output significantly increased to control levels after rhIL-1ra injection in the infected groups whereas no significant changes were observed after rhIL-1ra injection in the control groups.

In the present study, marked infiltration of inflammatory cells, such as polymorphonuclear and mononuclear cells, in the gastric mucosa spreading from the antrum to the body and formation of lymphoid follicles in the submucosa in the transitional zone between the antrum and body were observed in Mongolian gerbils infected with $H$ pylori. These histological findings were similar to the gastric mucosa of patients with $H$ pylori positive gastritis. ${ }^{36} 37$ IL- $1 \beta$ is released mainly from activated monocytes and macrophages. ${ }^{8}$ Therefore, infiltration and activation of monocytes and macrophages induced by $H$ pylori infection release IL- $1 \beta$, resulting in gastric acid hyposecretion.

IL-1 receptor antagonist binds to the IL-1 receptor and blocks the binding of both IL- $1 \alpha$ and IL- $1 \beta$ without inducing a signal of its own. ${ }^{8}$ The inhibitory effect of IL-1 $\beta$ on gastric acid

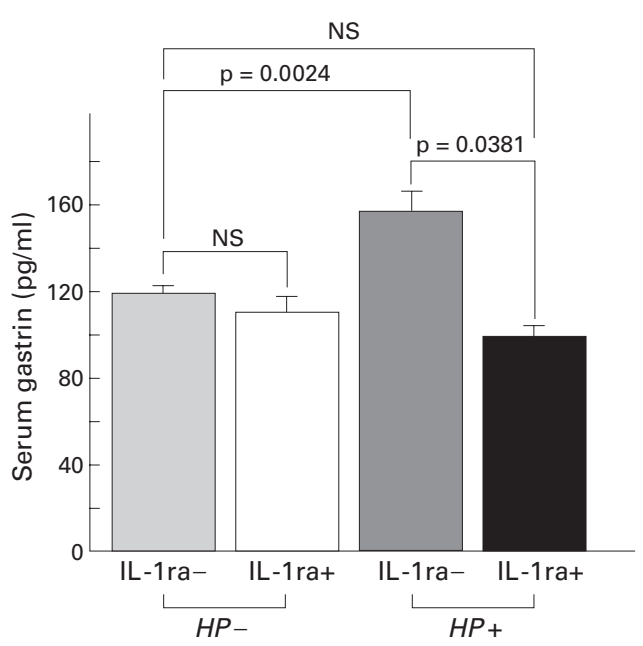

Figure 11 Serum gastrin levels with (+) or without (-) recombinant human $I L-1$ receptor antagonist (rhIL-1 ra) injection in the infected (Helicobacter pylori $(\mathrm{HP}+)$ ) and control (HP-) groups. Serum gastrin levels significantly decreased to control levels after rhIL-1 ra injection in the infected groups whereas no significant changes were observed after rhIL-1 ra injection in the control groups. 
secretion is suppressed by peripheral rhIL-1 ra injection in rat. ${ }^{31}{ }^{38}$ rhIL-1 ra has been used as a potent blocker of IL-1 receptors of Mongolian gerbils in a previous report. ${ }^{39}$ Human, rat, and mouse IL- $1 \beta$ genes have similar sequences. ${ }^{40}$ In the present study, we identified part of the gene sequence of the biologically active portion of Mongolian gerbil IL-1 $\beta$. There was a high level of conservation between human and Mongolian gerbil sequences. In addition, human, rat, and mouse IL-1ra genes have similar sequences. ${ }^{40}$ Therefore, rhIL-1 ra was assumed to work as an antagonist at the IL- $1 \beta$ receptor of Mongolian gerbils. As demonstrated in our study, gastric acid hyposecretion in the infected groups returned to control levels after injection of rhIL-1ra. These results suggest that IL-1 $\beta$ induced by $H$ pylori related body gastritis inhibits gastric acid hyposecretion.

In the present study, we showed that $H$ pylori infection decreased gastric acid secretion but increased the volume of gastric juices. Therefore, secretion of some acid neutralising factors, such as bicarbonate and mucus, was assumed to be increased. A recent study has shown that IL- $1 \beta$ increases prostaglandin production. ${ }^{41}$ Prostaglandins increase bicarbonate and mucus secretion and inhibit basal and gastrin stimulated acid secretion..$^{42}{ }^{43}$ Therefore, an increase in the volume of gastric juices in spite of decreased acid secretion may be mediated by prostaglandins, which are induced by IL- $1 \beta$.

We also determined serum gastrin levels in Mongolian gerbils infected with $H$ pylori with reference to IL- $1 \beta$. We showed that serum gastrin levels increased after $H$ pylori infection. Many possible factors associated with hypergastrinaemia in $H$ pylori infection have been reported. For example, the inhibitory effects of cholecystokinin on gastrin release were reduced by $H$ pylori infection. ${ }^{44}$ Luminal ammonia elevated plasma gastrin concentrations in rats. ${ }^{45}$ Cytokines, such as IL- $1 \beta$, IL-8, tumour necrosis factor $\alpha$, and interferon $\gamma$ release gastrin from rabbit, canine, and human antral $G$ cells in primary culture. ${ }^{4-48}$ Intragastric hypoacidity may induce hypergastrinaemia. ${ }^{49}$ In the present study, serum gastrin levels and mucosal IL-1 $\beta$ levels significantly increased after $H$ pylori infection. After rhIL-1ra injection, serum gastrin levels decreased to control levels with an increase in gastric acid output. These findings highlight two reasons for hypergastrinaemia: a direct effect of IL- $1 \beta$ on gastrin release from $\mathrm{G}$ cells or gastrin release corresponding to a decrease in intragastric acidity. The inhibitory effect of low $\mathrm{pH}$ on the release of gastrin was observed in $H$ pylori positive patients with and without duodenal ulcer disease, as well as in $H$ pylori negative patients. ${ }^{50}$ In the present study, after injection of rhIL-1ra, serum gastrin levels were decreased and gastric acid secretion was increased, although gastrin is a stimulant of acid secretion. Therefore, it is reasonable that IL- $1 \beta$ inhibits gastric acid secretion resulting in hypergastrinaemia in compensation for decreased acid secretion, and direct effects of IL-1 $\beta$ on gastrin release from $G$ cells appear to be of limited relevance in vivo.
In conclusion, we have confirmed that $H$ pylori infection causes gastritis from the antrum to the body which induces IL- $1 \beta$ in the gastric mucosa, which then inhibits gastric acid secretion resulting in hypergastrinaemia. Certainly, atrophy will spread out into the oxyntic mucosa, and parietal cell mass will decrease markedly, which contributes to gastric acid hyposecretion if the study period becomes longer. We also identified part of the sequence of a Mongolian gerbil IL-1 $\beta$ gene and determined mRNA levels of IL- $1 \beta$ in the gastric mucosa. Although we did not determine IL-1 $\beta$ release, it is considered that IL- $1 \beta$ levels correspond to mRNA levels. ${ }^{51}$ Therefore, IL-1 $\beta$ induced by $H$ pylor infection is assumed to inhibit gastric acid secretion.

Lastly, our results should be interpreted within the context of the limitations of our study regarding the use of Mongolian gerbils for the following reasons: when Mongolian gerbils were infected with $H$ pylori, the transitional zone between the antrum and corpus of the stomach was reported to gradually expand up into the fundic mucosa as the infection progressed..$^{52}$ This was similar to the phenomenon observed in patients with body gastritis. However, the number of viable $H$ pylori detected in the gastric mucosa of Mongolian gerbils was much less than that of humans infected with $H$ pylori and $H$ pylori (Sydney strain) infected mice. ${ }^{1453}$ Differences in sensitivity to $H$ pylori may account for the differences in numbers. ${ }^{53}$ Moreover, basal gastric acid output of Mongolian gerbils was low and approximately $1 / 15$ th of the output in rats. ${ }^{53}$ This lower basal acid secretion of Mongolian gerbils may explain why duodenal ulcer is not observed in this $H$ pylori infected animal model, in spite of many reports of development of gastric ulcer and gastric cancer. ${ }^{15} 165253$

Therefore, we consider this animal model is appropriate for the study of disorders with hyposecretion caused by $H$ pylori infection. Our study will be helpful to clarify the mechanisms by which body gastritis caused by $H$ pylori infection inhibits gastric acid secretion, which is now considered to be closely related to the development of gastric cancer. ${ }^{13}$

The study was supported by a Grant-in Aid for Scientific Research from the Ministry of Education, Science, Sports, and Culture, Japan. The abstract of the study was presented at the annual meeting of the AGA, San Diego, California, USA, May 2000. We thank Fumihiro Hirayama for technical advice.

1 Marshall BJ, Warren JR. Unidentified curved bacilli in the stomach of patients with gastritis and peptic ulceration. Stomach of patients with

2 Marshall BJ, Goodwin CS, Warren JR, et al. Prospective double-blind trial of duodenal ulcer relapse after eradication of Campylobacter pylori. Lancet 1988;2:1437-42.

3 Moss SF, Calam J. Acid secretion and sensitivity to gastrin in patients with duodenal ulcer: effect of eradication of Helicobacter pylori. Gut 1993;34:888-92.

4 El-Omar EM, Penman I, Dorrian CA, et al. Eradicating Helicobacter pylori infection lowers gastrin medicated acid secretion by two thirds in patients with duodenal ulcer. Gut 1993;34:1060-5.

5 El-Omar EM, Oien K, El-Nujumi A, et al. Helicobacter pylori infection and chronic gastric acid hyposecretion. Gastroenterology 1997;113:15-24.

6 Hurlimann S, Dür S, Schwab P, et al. Effects of Helicobacter pylori on gastritis, pentagastrin-stimulated gastric acid secretion, and meal-stimulated plasma gastrin release in the absence of peptic ulcer disease. Am $\mathcal{F}$ Gastroenterol
1998;93:1277-85. 
7 Furuta T, Baba S, Takashima M, et al. Effect of Helicobacter pylori infection on gastric juice $\mathrm{pH}$. Scand $\mathcal{f}$ Gastroenterol 1998;33:357-63.

8 Dinarello CA. Interleukin-1 and interleukin-1 antagonism. Blood 1991:77:1627-52.

9 Uehara A, Okumura T, Sekiya C, et al. Interleukin-1 inhibits the secretion of gastric acid in rats: possible involvemen of prostaglandin. Biochem Biophys Res Commun 1989;1: 1167-8.

10 Wallace JL, Cucala M, Mugridge $\mathrm{K}$, et al. Secretagoguespecific effects of interleukin-1 of gastric acid secretion. $A m$ f Physiol 1991;261: G559-64.

11 Noach LA, Bosma NB, Jansen J, et al. Mucosal tumor necrosis factor- $\alpha$, interleukin- $1 \beta$, and interleukin- 8 production in patients with Helicobacter pylori infection. Scand $f$ Gastroenterol 1994;29:425-9.

12 Yasunaga Y, Shinomura Y, Kanayama S, et al. Increased production of interleukin $1 \beta$ and hepatocyte growth factor may contribute to foveolar hyperplasia in enlarged fold gasmay contribute to foveolar
tritis. Gut 1996;39:787-94.

13 El-Omar EM, Carrington M, Chow WH, et al. Interleukin-1 polymorphisms associated with increased risk of gastric cancer. Nature 2000;404:398-402

14 Hirayama F, Takagi S, Kusuhara H, et al. Induction of gastric ulcer and intestinal metaplasia in Mongolian gerbil infected with Helicobacter pylori. F Gastroenterol 1996;31: 755-7

15 Watanabe $\mathrm{T}$, Tada $\mathrm{M}$, Nagai $\mathrm{H}$, et al. Helicobacter pylori infection induces gastric cancer in Mongolian gerbils. Gas troenterology 1998;115:642-8.

16 Hirayama F, Takagi S, Yokoyama Y, et al. Establishment of gastric Helicobacter pylori infection in Mongolian gerbils. $f$ Gastroenterol 1996;31 (suppl IX):24-8.

17 Dixon MF, Genta RM, Yardly JH, et al. Classification and grading of gastritis: The updated Sydney system. Am $\mathcal{f}$ Surg Pathol 1996;20:1161-81.

18 Telford JL, Macchia G, Massone A, et al. The murine interleukin 1 beta gene: structure and evolution. Nucleic Acids leukin 1 beta gene: $\mathrm{s}$

19 Bensi G, Raugei G, Palla E, et al. Human interleukin-1 beta gene. Gene 1987;52:95-101.

20 March CJ, Mosley B, Larsen A, et al. Cloning, sequence and expression of two distinct human interleukin-1 complementary DNAs. Nature 1985;315:641-7.

21 Sanger F, Nicklen S, Coulson AR. DNA sequencing with chain-terminating inhibitors. Proc Natl Acad Sci USA 1977;74:5463-7.

22 Matsuyama S, Koide Y, Yoshida T. HLA class II moleculemediated signal transduction mechanism responsible for the expression of interleukin-1 beta and tumor necrosis factor-alpha genes induced by a staphylococcal superantigen. Eur F Immunol 1993;23:3194-202.

23 Furuta T, Baba S, Takashima $\mathrm{M}$, et al. $\mathrm{H}^{+} / \mathrm{K}^{+}$-adenosine triphosphatase mRNA in gastric fundic gland mucosa in patients infected with Helicobacter pylori. Scand $\mathcal{f}$ Gastroenterol 1999;34:384-90.

24 Gutierrez O, Melo M, Segura AM, et al. Cure of Helicobacter pylori infection improves gastric acid secretion in patients pylori infection improves gastric acid secretion in patients

25 Haruma K, Mihara M, Okamoto E, et al. Eradication of Helicobacter pylori increases gastric acidity in patients with atrophic pstritis of the corpu- evaluation of $24-\mathrm{h} \mathrm{pH}$ atrophic gastritis of the corpu-evaluation of 24-h
monitoring. Aliment Pharmacol Ther 1999;13:155-62.

26 Jablonowski H, Hengels KJ, Kraemer K, et al. Effects of Helicobacter pylori on histamine and carbachol stimulated acid secretion by human parietal cells. Gut 1994;35:755-7.

27 Courillon-Mallet A, Launay JM, Roucayrol AM, et al. Helicobacter pylori infection: physiopathologic implications of $\mathrm{N}^{a}$-methyl histamine. Gastroenterology 1995;108:959-66.

28 Nompleggi DJ, Beinborn M, Roy A, et al. The effect of recombinant cytokines on $\left[{ }^{14} \mathrm{C}\right]$-aminopyrine accumulation by isolated canine parietal cells. F Pharmacol Exper Ther 1994;270:440-5.

29 Kondo S, Shinomura Y, Kanayama S, et al. Interleukin-1 beta inhibits gastric histamine secretion and synthesis in the rat. Am f Physiol 1994;267:G966-71.

30 Mugridge KG, Perretti M, Ghiara P, et al. Gastric antisecretory and antiulcer actions of IL-1 in rat involve different IL-1 receptor types. Am $\mathcal{f}$ Physiol 1995;269:G764-9.

31 Robert A, Oafssn AS, Lancaster C, et al. Interleukin-1 is cytoprotective, antisecretory, stimulates PGE2 synthesis by the stomach, and retards gastric emptying. Life Sci 1991;48:123-34.

32 Beales IL, Calam J. Interleukin $1 \beta$ and tumor necrosis factor $\alpha$ inhibit acid secretion in cultured rabbit parietal cells by multiple pathways. Gut 1998;42:227-34.

33 Prinz C, Neumayer N, Mahr S, et al. Functional impairment of rat enterochromaffin-like cells by interleukin $1 \beta$. Gastroenterology 1997;112:364-75.

34 Peek RM Jr, Miller GG, Tham KT, et al. Heightened inflammatory response and cytokine expression in vivo to $\mathrm{cagA}^{+}$ Helicobacter pylori strains. Lab Invest 1995;71:442-51.

35 Yamaoka Y, Kita M, Kodama K, et al. Induction of various cytokines and development of severe mucosal inflammation by cagA gene positive Helicobacter pylori strains. Gut 1997;41:442-51.

36 Blaser MJ. Helicobacter pylori and the pathogenesis of gastroduodenal inflammation. F Infect Dis 1990;161:626-33.

37 Hassal E, Dimick JE. Unique features of Helicobacter pylori disease in children. Dig Dis Sci 1991;36:417-23.

38 Hannum CH, Wilcox CJ, Arend WP, et al. Interleukin-1 antagonist activity of human interleukin-1 inhibitor. Nature 1990;343:33-40.

39 Ohtsuki T, Ruetzler CA, Tasaki K, et al. Interleukin-1 mediates induction of tolerance to global ischemia in gerbil hippocampel CA1 neurons. I Cereb Blood Flow Metab 1996;16:1137-42.

40 Eisenberg SP, Erewer MT, Verderber E, et al. Interleukin 1 receptor antagonist is a member of the interleukin 1 gene family: Evolution of a cytokine control mechanism. Proc Natl Acad Sci USA 1991;88:5232-6.

41 Bamba H, Ota S, Kato A, et al. Nonsteroidal antiinflammatory drugs may delay the repair of gastric mucosa by suppressing prostaglandin-mediated increase of hepatocyte growth factor production. Biochem Biophys Res Commun 1998;245:567-71.

42 Robert A. Cytoprotection by prostaglandins. Gastroenterology 1979;77:761-7.

43 Whittle BJR, Vane JR. Prostanoids as regulators of gastrointestinal function. In: Johnson LR, ed. Physiology of the gastrointestind

44 Konturek JW, Gillessen A, Konturek SJ, et al. Eradication of Helicobacter pylori restores the inhibitory effect of cholecystokinin on postprandial gastrin release in duodenal ulcer patients. Gut 1995;37:482-7.

45 Lichtenberger LM, Dial EJ, Romero JJ, et al. Role of luminal ammonia in the development of gastropathy and hypergastrinemia in the rat. Gastroenterology 1995;108:320-9.

46 Weigert N, Schaffer K, Schusdziarra V, et al. Gastrin secretion from primary culture of rabbit antral $G$ cell: stimulation by inflammatory cytokines. Gastroenterology 1996;110:147-54.

47 Beales I, Blaser MJ, Srinivasan S, et al. Effect of Helicobacter pylori products and recombinant cytokines on gastrin release from cultured canine G cells. Gastroenterology 1997; 113:465-71.

48 Beales IL, Post L, Calam J, et al. Tumor necrosis factor alpha stimulates gastrin release from canine and human antral G cells: possible mechanism of the Helicobacter pylori link. Eur f Clin Invest 1996;26:609-11

49 Fraser AG, Sawyerr AM, Hudson M, et al. Effects of ranitidine $150 \mathrm{mg}$ four times a day on 24-hour intragastric acidity and 24-hour plasma gastrin concentration. Dig Dis Sci 1994:39:91-6.

50 Karnes WE Jr, Ohning GV, Sytnik B, et al. Elevation of meal-stimulated gastrin release in subjects with Helicobacter pylori infection: reversal by low intragastric $\mathrm{pH}$. Rev Infect Dis 1991;13(suppl 8):S665-70.

51 Graves KL, Roman J. Fibronectin modulates expression of interleukin-1 $\beta$ and its receptor antagonist in human mononuclear cells. Am f Physiol 1996;271:L61-9.

52 Ikeno $\mathrm{T}$, Ota H, Sugiyama A, et al. Helicobacter pyloriinduced chronic active gastritis, intestinal metaplasia, and gastric ulcer in Mongolian gerbils. Am f Pathol 1999;154: $951-60$.

53 Keto Y, Takahashi S, Okabe S. Healing of Helicobacter pylori-induced gastric ulcers in Mongolian gerbils. Dig Dis Sci $1999 ; 44: 257-65$. 